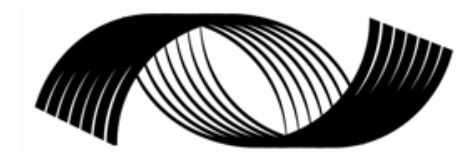

\title{
\begin{tabular}{llllllllllllllllllll}
$\mathrm{J}$ & $\mathrm{O}$ & $\mathrm{I}$ & $\mathrm{N}$ & $\mathrm{T}$ & $\mathrm{C}$ & $\mathrm{E}$ & $\mathrm{N}$ & $\mathrm{T}$ & $\mathrm{E}$ & $\mathrm{R}$ \\
\hline
\end{tabular} \\ AEI-BROOKINGS JOINT CENTER FOR REGULATORY STUDIES
}

\section{An Evaluation of the Quality of Impact Assessment in the European Union with Lessons for the U.S. and the EU}

\author{
Caroline Cecot, Robert Hahn, Andrea Renda, and Lorna Schrefler ${ }^{*}$
}

Working Paper

December 2007

* Ms. Cecot is a research associate at Reg-Markets.org. Mr. Hahn is founder and executive director of RegMarkets.org and a scholar at AEI. Mr. Renda is a senior research fellow at the Centre for European Policy Studies, where he is head of the Regulatory Affairs Programme. Ms. Schrefler is a research fellow at the Centre for European Policy Studies. The authors would like to thank Scott Farrow, Robert Litan, Paul Tetlock, and Scott Wallsten for helpful suggestions. Molly Wells provided valuable research assistance. This research was supported by the AEIBrookings Joint Center and Reg-Markets.org. The usual disclaimer applies. (C) 2007 by the authors. All rights reserved. 


\begin{abstract}
Governments throughout the world are requiring greater use of economic analysis as a way of informing key policy decisions. The European Union now requires that an impact assessment be done for all major policy initiatives. An evaluation of the EU system could provide lessons for the U.S. and determine whether the EU is allocating resources for analysis efficiently.

This paper provides a comprehensive analysis of the use of impact assessment in the European Union since its inception, using the largest available dataset. We score these assessments using a number of objective measures of quality, such as whether a particular assessment provides information on costs, benefits, or alternatives. In addition, we provide the first empirical evaluation of the EU principle of proportionate analysis, which calls for the application of more rigorous analytical standards to important policy initiatives.

In general, we find that recent EU impact assessments include more economic information, but many important items are still missing. We also provide evidence that the quality of EU impact assessment increases with the expected cost of the proposal, which is consistent with the proportionality principle. Furthermore, while we find that the average quality of EU assessments lags behind U.S. assessments, we cannot reject the hypothesis that the analysis done for important initiatives in the EU is of similar quality to the analysis done in the U.S. Finally, we offer concrete suggestions on how the EU and U.S. might improve their evaluation processes by learning from each other.
\end{abstract}




\section{An Evaluation of the Quality of Impact Assessment in the European Union with Lessons for the U.S. and the EU Caroline Cecot, Robert Hahn, Andrea Renda, and Lorna Schrefler}

\section{Introduction}

Governments throughout the world are requiring greater use of economic analysis as a way of informing key policy decisions. In 1981, President Reagan set up an office within the U.S. Office of Management and Budget (OMB) whose primary aim was to improve the quality of regulations. More recently, in 2002, the European Union required that government departments provide an impact assessment for all major policy initiatives (European Commission, 2002).

A central feature of the U.S. and EU policy evaluation process is the use of benefit-cost analysis and related tools. Because benefit-cost analysis can require considerable resources, it is important to determine when its benefits exceed its costs. The U.S. addresses this problem by requiring a regulatory impact analysis (RIA), which is supposed to include a benefit-cost analysis, for "major" regulations only. Major regulations typically have annual economic impacts that exceed $\$ 100$ million (OMB, 2005). The idea is that subjecting major regulations to careful analysis is worthwhile.

In contrast, the European Union requires an impact assessment (IA) for a wide array of policy initiatives, but it does not clearly specify the standards for analysis in particular cases. The assessments are supposed to analyze the likely economic, social, and environmental impacts of specific policies. The EU applies a principle of proportionate analysis, which calls for the application of more rigorous analytical standards to important policy initiatives. ${ }^{1}$

The usefulness of a particular analysis is likely to depend on its quality; if done well, analysis can help decision makers manage risk and set priorities. Therefore, to make prudent recommendations for improving the use of benefit-cost analysis in policy settings, we need some measure of how well such analyses are actually done. ${ }^{2}$ In addition, we believe there are substantial opportunities for agencies in different countries to borrow policy innovations from each other. An evaluation of the EU system could provide lessons for the U.S.

This paper provides a comprehensive analysis of the use of impact assessment in the European Union since its inception, using U.S. assessments as a benchmark for comparison. We examine the quality of the 111 EU impact assessments by scoring them using a number of objective measures of quality, such as whether a particular assessment provides any quantitative information on costs, benefits, or alternatives. ${ }^{3}$ This is the largest dataset of its kind.

In general, we find that recent EU impact assessments include more economic information, but many are still missing important economic components. We also provide evidence that the quality of EU impact assessment increases with the expected cost of the proposal, which is consistent with the proportionality principle.

\footnotetext{
${ }^{1}$ We refer to the principle of proportionate analysis as the proportionality principle.

${ }^{2}$ We will not debate the merits of the application of economic analysis, such as benefit-cost analysis, to problems in public policy. Sunstein (2002) and Breyer (1993) offer insightful defenses of economic approaches to analyzing important public policy issues. We also do not measure the impact of the benefit-cost process, though we think this is an important area of inquiry (Farrow, 2000).

${ }^{3}$ We provide more details on this approach below.
} 
Previous studies have determined that the quality of the European Commission's IAs is low and likely to be much lower than the quality of U.S. RIAs. In contrast, we find that the quality of EU impact assessments that report total costs greater than $\$ 100$ million is similar to that of regulatory impact analyses done in the U.S. for major regulations.

The remainder of this paper is organized as follows. Section II of the paper provides some background on the U.S. and EU experience with economic analysis. Section III reviews methods for assessing quality and the results of early assessments of EU impact assessments and U.S. regulatory impact analyses. Section IV describes the results of our analysis, including possible improvements to EU impact assessments. Section V concludes and offers suggestions on how the EU and U.S. might improve their evaluation processes by learning from each other.

\section{Regulatory Evaluation in Europe and the U.S.}

The European Union introduced impact assessment in 2002 as a way to improve policy design. The United States has required regulatory impact analyses since 1981. We provide a brief discussion of both approaches to highlight key similarities and differences.

\section{A. The U.S. Example}

The U.S. was the first country to require economic analysis of at least some proposed regulations. Over the last two decades, both Congress and the Executive Branch have initiated policies aimed at improving assessments of the economic impacts of regulation and encouraging the development of more effective and efficient regulations (Hahn et al., 2000). For example, Presidents Ronald Reagan, George H. W. Bush, Bill Clinton, and George W. Bush directed all agencies to perform economic analyses of major regulations that show whether a regulation's benefits are likely to exceed its costs and whether alternatives to that regulation would be more effective or less costly. Each president also attempted to increase agency accountability for decisions by requiring that OMB review all major regulations. More recently, Congress has also supported greater regulatory accountability. For example, Congress inserted analytical requirements and accountability provisions into a number of laws, such as the Unfunded Mandates Reform Act of 1995. In addition, Congress has passed laws that require OMB to produce regular reports on the costs and benefits of federal regulation (e.g., OMB, 2005).

Early efforts to improve the regulatory process can be traced to Presidents Nixon, Ford, and Carter, but President Reagan was the first to implement a formal process that required economic evaluation (Weidenbaum, 1997). The most prominent and far-reaching of the regulatory accountability efforts were President Reagan's Executive Order 12291 and President Clinton's Executive Order 12866. ${ }^{4}$ Both executive orders require agencies to prepare a regulatory impact analysis for all major federal regulations. ${ }^{5}$ The RIA is then sent, along with the

\footnotetext{
${ }^{4}$ President George W. Bush recently amended Executive Order 12866. The basic thrust of the new order is the same with regard to economic analysis of regulations. But the new order also requires more careful scrutiny of regulatory guidance from agencies. Hahn and Litan (2007) provide a summary of the changes.

5 There are subtle differences between the two executive orders. Clinton's Executive Order 12866 places more emphasis on distributional concerns and public transparency of the regulatory process. Executive Order 12866 also requires agencies to show that the benefits “justify” the costs, in contrast to Reagan's Executive Order 12291, which requires that the benefits "outweigh" the costs. Both allow for analyzing some effects in qualitative terms only. Reagan's Executive Order 12291 acknowledges that some effects “cannot be quantified in monetary terms,” while
} 
proposed regulation, to analysts at the OMB, who review the proposal. The OMB either offers suggestions for improving the proposal or accepts it as is. Such centralized oversight can help with interagency coordination, setting priorities, and implementing more cost-effective and economically efficient regulation.

OMB has issued guidelines and memos instructing agencies on how to comply with the relevant executive orders (OMB, 1992; OMB, 1996). The EPA also issued its own set of guidelines, detailing how RIAs should comply with the executive orders (EPA, 1983; Snyder, 1996). The basic instructions, such as quantifying as many costs and benefits as possible and evaluating alternatives, have remained the same over the past twenty-five years.

\section{B. European Regulatory Assessment}

Efforts to improve regulatory accountability in Europe are more recent. In 1986, the United Kingdom introduced compliance cost assessment, which provided an estimate of the impact of proposed legislation on firm costs. It did not implement a detailed benefit-cost procedure until 1998 (Renda, 2006). Four years later, within the framework of the Better Regulation package, the European Commission (EC) of the EU, the body charged with drafting legislative and policy proposals, introduced the impact assessment program as a tool to increase the quality of policy decisions (EC, 2002). After a two year trial period, the system was relaunched in 2005 with more refined IA guidelines and a stronger emphasis on the quality of economic analysis (EC, 2005).

The Commission requires an impact assessment for all initiatives included in the Annual Policy Strategy or the Work Program, including many regulations, directives, decisions, and communications (EC, 2002). ${ }^{6}$ Thus, economic analysis is not limited to major regulations, as it is in the U.S. The EU makes far-reaching assessment manageable through the proportionality principle, where the depth of the analysis is proportional to the likely impact of the initiative (EC, 2004). EU impact assessments are also required to address the issue of subsidiarity-that is, whether the initiative would be best carried out by the Commission or at the member state level (EC, 2002).

The broad scope of EU impact assessment includes binding legal instruments (regulations, directives, and decisions) and nonbinding legislative proposals (communications, White Papers). ${ }^{7}$ Although regulations, directives, and decisions are all binding, their effect is slightly different. A regulation is binding in its stated form for all Member States. The general result of a directive is also binding, but the choice of the form and method is typically left to the individual Member State. A decision is like a regulation, except that it is addressed to specific individuals. Communications and White Papers are usually proposals to the community that may lead to European Union action, but are not binding.

Although the coverage is very broad, the impact assessment model does not apply to regulations or legislation implemented by individual member states. Most member states today apply some form of impact assessment on their own proposed legislation, but the model is different from the one adopted at EU level, and often less sophisticated (Renda, 2006). We focus

Clinton's Executive Order 12866 specifically calls for quantifiable measures "to the fullest extent that these can be usefully estimated.”

${ }^{6}$ Some types of initiatives are excluded from impact assessment in the EU, such as Green Papers, periodic Commission decisions and reports, and technical updates. See Communication from the Commission (2002). For a more detailed treatment of the European experience, see Renda (2006).

${ }^{7}$ These definitions were found on Eur-Lex, Europe's law database, available at http://eur-lex.europa.eu/. 
our analysis on IAs on binding initiatives only (regulations, directives, and decisions), since they are more similar to U.S. regulations. ${ }^{8}$

Originally, the Commission instructed departments of the EU responsible for specific areas (Directorate Generals, or DGs) to prepare a preliminary IA. The Commission then selected proposals that should undergo a more detailed analysis, called an extended impact assessment. The Commission took into account whether the proposal was likely to have substantial social, economic, and environmental impact and whether the proposal represented a major policy reform in one or several sectors (Renda, 2006). In 2004, the Commission replaced the term "extended impact assessment" with "impact assessment," because even in the extended stage, an IA might not be very detailed if the initiative's impact is not significant (EC, 2004). If used correctly, the proportionality principle can allocate resources to the assessment of the most important initiatives.

The Directorate General in charge of the IA consults interested parties, including other relevant directorates, and analyzes the impacts of the proposal (EC, 2005). The IA is then sent along with the proposal to the Council and the Parliament, the two main decision-making bodies of the EU, for discussion (OMB, 2006). The IA typically presents a preferred option but the final decision on a proposal rests with the Parliament and the Council.

The EU updated and improved its guidelines for using economic analysis to evaluate regulatory options in June 2005 (EC, 2005). The guidelines present a set of basic questions, minimal analytical standards, and a common reporting format (EC, 2002). The department in charge of the analysis is required to express impacts "as concretely as possible in qualitative, quantitative, and where possible, monetary terms” (EC, 2002). There are some guidelines for quantitative analysis, such as using a particular discount rate (e.g., 4\%) or the value of a statistical life (€1.0 million), just as in the U.S. In November 2006, following the results of an ex post evaluation of the IA system, the European Commission created an independent board that reviews IAs and ensures consistency and quality, though its opinions are not binding (Impact Assessment Board). The Board began issuing its opinions in early 2007.

\section{Evaluating the Quality of Impact Assessment}

This section discusses our method for assessing the quality of EU impact assessments as well as what is known about their quality.

\section{A. Method}

Currently, there are three ways to assess the quality of economic analyses. One is to use experts to examine the assumptions and results of a particular analysis. This method allows for in-depth analysis of particular issues germane to a specific regulation. It can also differentiate an analysis that is of bad quality because it is fundamentally wrong in its assumptions from an analysis that is of bad quality because it does not include key parameters or consistent modeling assumptions. The main disadvantage of this approach is that the results may be subjective, meaning that they are not easily generalized or replicated.

\footnotetext{
${ }^{8}$ They also appear to be of higher quality. Impact assessments on binding initiatives were associated with significantly higher ( $5 \%$ level) scores on an index that summarized the reporting of a point or range estimate of total costs, a point or a range estimate of total benefits, and a calculation of either net benefits or cost effectiveness.
} 
A second approach is to use an estimate of some parameter, such as net benefits or cost effectiveness, from an ex ante analysis and compare it with an ex post assessment (Harrington et al., 2000; OMB, 2005). This approach has the benefit of using an observed measure to gauge the quality of the economic analysis, with the assumption that the ex post estimate is a better measure of the actual impact of the policy. The greater the similarities between the two measures, the more accurate the ex ante analysis was in predicting economic impact and, hence, the better it was as a decision-making tool. The main disadvantages of this approach are that it is contingent on the available information at the time of the study and it presumes ex post estimates are more accurate, which may or may not be true. For any specific study, random outcomes create deviations from the expected value that may have been reported ex ante. In addition, because ex post studies are costly, relatively few are performed. It would be hard to use this approach to examine the quality of many impact assessments.

A third approach is to use a "scorecard" to assess whether an analysis meets key objective criteria such as whether it monetized at least some costs and benefits, whether it considered alternatives, and whether it used consistent modeling assumptions. ${ }^{9}$ We believe any high-quality analysis should contain all or most of these criteria. ${ }^{10}$ The advantages of this approach are that it is easily generalized, replicable, and inexpensively allows comparison of a large number of different analyses. The main disadvantage of this approach is that a score may not always provide a useful measure of quality. For example, an impact assessment can score highly but still be of poor quality if its estimates are inaccurate. Similarly, an impact assessment can receive a low score but still be of relatively good quality if many of the items that it did not include were unknowable or difficult to determine. Though an economic analysis that experts might agree was of high quality could theoretically get a low score on the scorecard, we believe this is unlikely. Despite these drawbacks, we believe that the scorecard approach is useful. For simplicity, we refer to scores on the scorecard as an indication of the quality of the economic analyses.

Previous studies have used the scorecard approach on both U.S. and EU economic analyses (Hahn et al., 2000; Hahn and Dudley, 2007; Renda, 2006). Hahn et al. (2000) were the first to use this scorecard approach to analyze regulatory impact analyses in the U.S. ${ }^{11}$ Hahn and Dudley (2007), which provides the most recent analysis of U.S. data, focused on EPA RIAs across three presidential administrations. They found that scores are generally low, meaning that a significant percentage of the analyses done by the EPA are not consistent with elements of OMB guidance and standard economic practice because they do not report some basic economic information. In addition, statistical analysis revealed no significant differences among scores for RIAs across time, administration, and offices within the EPA.

\section{B. Early Evaluations of the Quality of EU Impact Assessments}

Researchers are beginning to evaluate the EU system, and the results appear to have some similarities with the United States. For example, several impact assessments fail to discuss many important categories of information.

\footnotetext{
${ }^{9}$ See Table 1 for a complete list of scorecard items.

${ }^{10}$ See the Government Accountability Office (GAO) (2005), discussing why standardization of criteria is important in benefit-cost analysis. The GAO advocates a similar use of a scorecard to synthesize information consistently.

${ }^{11}$ Morrall (1986) first used information from regulatory impact analyses to calculate the cost effectiveness of various regulations in the U.S., demonstrating the need for reform. Similar approaches have been used by Tengs $e t$ al. (1995) and Tengs and Graham (1996).
} 
One of the earliest investigations by Lee and Kirkpatrick (2003) concluded that the first six impact assessments completed by the European Commission were "disappointing." Opoku and Jordan (2004), Vibert (2004), and Lussis (2004) each found considerable room for improvement in EU IAs as well. Vibert analyzed the first 20 IAs performed by the European Commission. He used a scorecard approach similar to ours and found that only half of the IAs quantified costs and benefits, only 11 included information on market alternatives, and only two had provided for peer review. Vibert (2004) concluded that the impact assessment method is a positive step toward better decision making, but that some aspects, such as the market analysis and the consultation process, need to be improved. Opoku and Jordan (2004) analyzed the 41 IAs completed in 2003 and 2004 and concluded that improvements, such as clearer guidelines and more thorough consultations, are necessary to resolve some of the deficiencies. Lussis (2004) examined 13 IAs and argued that there is a "methodological blank" in the identification and assessments of impacts and that there is a need for greater consistency.

More recently, the Environmental Assessment Institute (IMV, 2006) studied 58 IAs in 2004 and 2005. They concluded that the assessments in their study "do not in general give an overview of costs and benefits associated with the proposals analysed” (IMV, 2006).

Finally, Renda (2006) analyzed the first 70 IAs, from January 2003 through June 2005. By examining summary statistics, he found that impact assessments frequently do not contain important economic information and that there appears to be a decrease in quality and comprehensiveness of assessment over time. His results were based on a scorecard similar to the one used in Hahn and Dudley (2007). Our dataset includes the 47 IAs on binding initiatives from Renda (2006) and adds 64 more IAs, making it the largest assembled dataset of its kind.

Our data includes all impact assessments on binding initiatives between January 2003 and June 2005, and between January 2006 and October 2007. Three individuals scored groups of impact assessments. One individual then scored a subset of all of the IAs and compared the results to ensure consistency across scorers. The scores on the items that we summarize in this paper were consistent between scorers about $99 \%$ of the time.

\section{The Proportionality Principle}

The EU impact assessment system introduces a proportionality principle, where the depth and quality of an assessment is supposed to be related to the likely impact of the proposal. The advantage of the EU system is that it allows the European Commission to analyze a much broader range of initiatives. Impact assessment is not binary as it is in the U.S. and there is more flexibility and discretion given to the analysts. ${ }^{12}$ The disadvantages are that the system is difficult for researchers to evaluate and difficult for the public and stakeholders to hold the European Commission accountable for low quality impact assessments. The basic problem is that the Commission does not define its standards for any particular analysis clearly.

The European Commission gives no specific guidance to analysts on the level of analysis that any initiative should receive. In August 2006, the Commission organized a comprehensive, external evaluation of the IA system. The Evaluation Partnership (2007) summarized results from hundreds of surveys of different stakeholders and analyzed a representative sample of 20 IAs from 2003 to 2006. They found that $56 \%$ of EC officials disagreed with the statement: "It is

\footnotetext{
${ }^{12}$ In practice, there appears to be a great deal of discretion in the U.S. system, as evidenced by the wide variability in the quality of RIAs for economically significant regulations (Hahn, 1996).
} 
sufficiently clear how to implement the principle of proportionate analysis.”13 ${ }^{20}$ ly $20 \%$ agreed with the statement. ${ }^{14}$ This confusion may be due to the fact that policies to be analyzed are not ranked on the basis of their economic significance before undergoing analysis. Rather it is up to each individual analyst to discern the appropriate level of assessment.

Moreover, an analyst does not have to report his or her assessment of the importance of the regulation, presenting a formidable challenge to researchers trying to measure the progress of the European system. It is difficult for an outsider to make any inferences about the quality of an assessment without knowing the expected impact of the proposal, as understood by the analyst. Even if the European Commission believes that there is a problem with its impact assessment system, it cannot tell whether the problem is that its analysts incorrectly or inconsistently determine expected impacts or that they do the analyses poorly, perhaps lacking adequate training. ${ }^{15}$

Because we feel that an assessment of quality is very important to the usefulness of an impact assessment program, we undertake this project despite no ex ante information about the principle of proportionate analysis.

\section{Results}

Our results demonstrate that EU impact assessments are improving over time, but many are still missing important economic information. We also find that the quality of EU impact assessments that report total costs greater than $\$ 100$ million is similar to that of regulatory impact analyses in the U.S. Finally, we provide evidence that the quality of EU impact assessment increases with the expected cost of the proposal, which is consistent with the proportionality principle. This section describes these results in more detail.

Table 1 includes summary statistics on the 15 items we felt were most important to a decision maker. They include: whether the IA stated, monetized, and quantified benefits and costs; whether the IA included a measure of total benefits, costs, and net benefits or cost effectiveness; whether the IA considered alternatives; whether the IA quantified or monetized benefits and costs of the alternatives; and whether the IA calculated net benefits or cost effectiveness of the alternatives. To measure overall quality, we create an index of these 15 items, normalizing it to range from 0 to $1^{16}$

In the EU, the quality of an impact assessment should be a function of the impact of the proposal, assuming the proportionality principle is followed. Unfortunately, there is no ex ante measure of a proposal's expected impact or the level of analysis that might be required as a result of the proportionality principle. Thus, it is difficult to analyze whether the quality of analysis evaluating a particular policy is consistent with the proportionality principle.

\footnotetext{
13 This statistic includes those who “disagreed” and “disagreed strongly.” The Evaluation Partnership (2007) surveyed 89 Commission officials.

14 This statistic includes those who "agreed” and "agreed strongly." Twenty percent of officials were neutral and the rest did not know. The Evaluation Partnership (2007) also surveyed entire departments and found that 45\% "disagreed" or "disagreed strongly" with the statement. Twenty percent of departments "agreed” or "agreed strongly" and 30\% were neutral.

15 The Evaluation Partnership (2007) analysis suggests that both might be occurring. After analyzing 20 representative impact assessments from 2003 to 2006, they found that analysts frequently assess impacts disproportionately and with little depth. They use criteria similar to Hahn and Dudley (2007) in their evaluation, assessing the "quantification of impacts" and "the monetization of impacts," for example.

${ }^{16}$ Normalization means that an IA that includes all the scorecard items in the index receives a score of 1 for that index.
} 
We can gain some insight into whether the proportionality principle is likely to have been followed if we make one assumption: that over the five years that we analyze, the fraction of high impact proposals in any given year remains roughly constant or is distributed randomly. Thus, if we observe an increase in average scores on the index over time, we can reasonably attribute this increase to better impact assessments. Such an increase would also mean that many early impact assessments were likely lacking an appropriate level of assessment. If the actual level of high impact proposals were decreasing over time but we observe an increase in average scores, our conclusion would be even stronger. If the actual level were increasing and we observe an increase in average scores, then our conclusion could hold, but the results might also be explained by the fact that more significant policy proposals are being analyzed more carefully. There is no reason, based on first principles, to expect the fraction of high impact proposals would be increasing from January 2003 to October 2007.

\section{Conclusion 1: Recent impact assessments include more important economic information.}

We find that EU impact assessments include more economic information in the last two years. Figure 1 presents these results graphically. In 2003, the 15 IAs averaged a score of 0.40 on this index, while in 2007, the 25 IAs averaged a score of 0.55 on this index. This difference is statistically significant at the $10 \%$ level.

We confirm this observation using statistical analysis. We run an ordinary least squares (OLS) regression on the EU impact assessments. The dependent variable is the score on the index, and the independent variable is the linear time trend. According to the OLS regression, the magnitude of the impact on the index score is that IAs report about one more item of interest each year, significant at the 5\% level. We run another regression where we include dummy variables for the type of initiative (regulation, decision, or directive) and dummies for the two most common lead departments (the Environment and the Justice, Freedom, and Security departments). The linear time trend becomes highly significant at the $1 \%$ level. In comparison, Hahn and Dudley (2007) did not find a robustly significant time trend for the U.S. RIAs.

One possible criticism of our result is that it is highly dependent on our particular choice of a quality index. While the choice of an index is arbitrary, we illustrate that our result is robust to alternative measures. In particular, we focus on three unambiguously important parts of a benefit-cost assessment: the consideration of costs, benefits, and alternatives. We individually evaluated the quantification and monetization of impacts in these three categories and found that the EU improved its quantification and monetization of the costs of the proposal and its alternatives. The data suggests that there is further room for improvement in providing a monetary estimate of benefits of the proposal and its alternatives.

The improvement in the consideration of costs is the most apparent. In the last two years, almost every IA done on a binding initiative has included at least some qualitative information on costs, compared to about $70 \%$ of IAs previously. In addition, while only about $40 \%$ of IAs monetized some costs of the proposal in 2003, almost $80 \%$ of IAs monetized some costs of the proposal in 2007. The improvement in considering costs, quantifying costs, and monetizing costs over time is statistically significant at the 1\% level. Figure 2 summarizes this observation.

Consideration of benefits, however, appears to have remained roughly the same from January 2003 to October 2007. Unlike costs, EU IAs have always described benefits at least qualitatively. Interestingly, the quantification and monetization of benefits appears to have declined through 2005 and has increased only recently. Overall, the trend is not significantly 
different from zero. When we include a quadratic time trend along with a linear time trend in the regression, both trends are significantly different from zero at the $10 \%$ level. The linear time trend is significantly negative and the quadratic time trend is significantly positive. The reason for the U-shaped curve may be related to the difficulty inherent in quantifying and monetizing benefits, or it may reflect a need for more training in the monetization of benefits. ${ }^{17}$ Figure 3 summarizes our observations graphically.

Although the EU impact assessments frequently considered at least one alternative, usually the alternative of not regulating, the time trend is significantly positive at the $5 \%$ level. More apparent is the increase in the quantification and monetization of costs of alternatives, which is significant at the $1 \%$ level. Figure 4 summarizes these results. Nonetheless, we believe that there may be some room for improvement in the consideration of costs of alternatives. In 2006 and 2007, the EU monetized costs in close to 80\% of IAs on binding initiatives. For the same years, the EU monetized costs of alternatives in less than $60 \%$ of IAs on binding initiatives. If a proposal were important enough to warrant monetization of costs, it seems that monetization of its alternatives should also have been undertaken for comparison.

Like the quantification and monetization of benefits, the quantification and monetization of benefits of alternatives appears to decline and only recently increase. This result may also be related to the difficulty in quantifying and monetizing benefits. Still, the monetization of the benefits of the proposal is about $40 \%$, while the monetization of the benefits of alternatives is closer to $20 \%$, which implies room for the EU to improve in this area. It seems plausible that if it was possible to monetize the benefits of a proposal, it would be possible and helpful to monetize the benefits of the alternatives.

Although the European Commission has improved its impact assessment of some of the most important items in a benefit-cost analysis, the reporting of other items has remained constant from January 2003 to October 2007. It appears that the Commission might not place a high value on these items. Though we do not include these items in our index, we believe that they are important for decision makers.

Most impact assessments now include an executive summary, but many still do not summarize the costs and benefits of the proposal in the executive summary. Figure 6 summarizes these results. The percentage of IAs that provide information on costs and benefits in the executive summary is much lower than the percentage that monetize at least some costs and benefits. The Evaluation Partnership (2007) found that decision makers frequently commented that the presentation of information in the IA made it difficult for them to locate key information. We believe that presentation is one of the most important areas in which the EU can improve. Summary cost and benefit information in the executive summary will make it easier for EU decision makers to focus on the bottom line of the study and know what information to expect in the full study.

Despite significant strides in monetizing costs and benefits, the EU impact assessments rarely include an estimate of net benefits or cost effectiveness. Figure 5 summarizes these results. The reason could simply be that analysts are uncomfortable including this estimate when many impacts could not be monetized. We believe, however, that an estimate of net benefits or cost

\footnotetext{
${ }^{17}$ Jacobs (2006) suggests that IA quality may follow a U-shape curve over time, which appears to be supported by our results for benefits. He reasons that the initial expansion of analysis leads to a decline in quality, but that training and experience eventually catches up and quality rises again. This is plausible in the consideration of benefits because benefit quantification and monetization is usually more difficult and may require specific training.
} 
effectiveness combined with a list of the impacts that could not be monetized can make the interpretation of an impact assessment easier for decision makers.

Finally, analytical assumptions are important for consistency across impact assessments and across time. The real value of a currency, for example, can change over time. Noting the Euro year used in monetizing impacts in the analysis will make it easier for the EU to assess the real aggregate costs and benefits of its initiatives over the course of several years. Figure 7 summarizes the percentage of IAs that identify the Euro year. Less than $10 \%$ of IAs identify the Euro year, a simple and necessary task for any IA that monetizes anything. ${ }^{18}$

Conclusion 2: The quality of EU impact assessments that report total costs greater than $\$ 100$ million is similar to that of regulatory impact analyses in the U.S.

To put the quality of impact assessments into context, we compare the percentage of EU IAs that report important items to the percentage of U.S. regulatory impact analyses that report them, using the dataset of environmental RIAs analyzed in Hahn and Dudley (2007). We find that EU IAs frequently lack important economic information and that U.S. RIAs seemingly outperform EU IAs in every measure, often by a large margin. ${ }^{19}$ In fact, the only exception is the consideration of alternatives, where EU IAs outperform the U.S. RIAs. These results, summarized in Table 2, are in line with previous assessments of the overall quality of the EU IAs.

Of course, the proportionality principle could explain these summary results. In this section, we attempt to bound the proportionality principle by analyzing the data in more detail.

We assess the application of the proportionality principle in two ways. First, we compare U.S. RIAs to EU IAs on initiatives that would be significant in the U.S. Although this would not tell us if the EU were failing relative to its own metric, it can shed light on whether the depth of analysis of proposals of similar impact is different in the EU and the U.S. Second, we examine whether quality increases with increases in the reported cost of a policy.

We compare U.S. and EU assessments by analyzing only the binding impact assessments from January 2003 to October 2007 that reported total costs greater than $\$ 100$ million. ${ }^{20}$ This makes a dataset of 22 IAs. We compare these to the 74 Hahn and Dudley (2007) environmental RIAs. ${ }^{21}$ We note that this method is biased in favor of the EU IAs since we consider only those that gave an estimate of total costs, which may already indicate a higher quality subset of IAs. We also note that the comparison between the two groups of assessments is not as sharp as one might like. In particular, the assessments differ in terms of focus, time period, initial assessors,

\footnotetext{
${ }^{18}$ Other analytical assumptions, such as noting the discount rate, are important for ensuring consistency between departments and different IAs. We do not summarize the percentage of IAs that identify a discount rate because some IAs might not require any discounting.

${ }^{19}$ An F-test on all the items demonstrated that the hypothesis of equal means could be rejected at the $1 \%$ level. Separate tests for the difference in means between U.S. and EU for each measure rejected the hypothesis of equal means for all items at the $1 \%$ level, except the statement of benefits. The mean for the EU IAs was significantly greater than the mean for the U.S. RIAs only in the consideration of alternatives.

${ }^{20}$ We use total costs because more IAs summarized costs than benefits. In the U.S., an RIA is considered to major if costs or benefits are greater than or equal to $\$ 100$ million. Technically, we include all IAs with costs greater than or equal to $\$ 100$ million, although in practice, no IAs reported costs exactly equal to $\$ 100$ million.

${ }^{21}$ We do not limit the Hahn and Dudley (2007) RIAs to those reporting total costs greater than $\$ 100$ million because all the RIAs in the dataset were expected to have an economic impact over $\$ 100$ million, which can include costs or benefits. Limiting the U.S. sample to those that reported total costs over \$100 million does not change our qualitative results.
} 
and scorers. These caveats notwithstanding, this is the best data available with which to make such a comparison.

We find that the quality of the subset of impact assessments reporting costs greater than $\$ 100$ million dollars is very similar to that of the U.S. regulatory impact analyses. Table 2 summarizes our results. The EU IAs and the U.S. RIAs both average a score of 0.71 on the index, and the percentage of IAs and RIAs reporting the individual scorecard items is also very similar. For most items, the difference in means is not statistically significant at the $10 \%$ level. Specifically, a test on the difference in means for each measure demonstrated that the hypothesis of equal means could only be rejected for three items. The EU IAs were significantly more likely to report total costs and consider alternatives (at the $10 \%$ level for both). The U.S. RIAs were significantly more likely to quantify benefits (at the $1 \%$ level), though the monetization of benefits was roughly the same. An F-test on the remaining items demonstrated that the hypothesis of equal means for all items could not be rejected at the $10 \%$ level.

Our result suggests that when EU analysts estimate that a policy costs more than $\$ 100$ million, their reporting on key dimensions of quality is similar to their U.S. counterparts. We cannot determine whether the impact assessments that did not report total cost information actually had impacts greater than $\$ 100$ million. Therefore, we cannot determine whether the proportionality principle is applied correctly when analysts decide whether or not to monetize total costs. Our analysis only suggests that, after controlling for the impact of proposals for which we do have an estimate of total cost, the quality of EU IAs is similar to that of U.S. RIAs. Because the quality of the entire sample of IAs is much lower than that of U.S. RIAs, our results imply that the quality of all relevant IAs might be similar to that of U.S. RIAs, or lower.

Conclusion 3: The quality of impact assessment increases with the expected cost of the proposal, after controlling for time.

If the proportionality principle were being applied correctly, one would expect to see a positive correlation between quality scores and higher levels of impact, such as cost. Figure 8 plots the scores on the index by the cost of the proposal. To determine if the quality of an impact assessment increases with the cost of a proposal, we run an ordinary least squares (OLS) regression on the subset of EU IAs with an estimate of total costs. This time, we do not limit the sample to impact assessments with costs greater than $\$ 100$ million, increasing the subset of IAs to 32. The dependent variable is the score on the index, and the independent variable is the natural logarithm of the cost. We do not use a simple cost variable because, though highly significant at the $1 \%$ level, the result is driven by two outliers. We use the logarithm of the cost in order to reduce the effect of the outliers. We find that the coefficient on the logarithm of the cost is positive and significant at the $10 \%$ level, but only after we include a linear time trend in the regression, which is also positive and significant at the $10 \%$ level. This means that, after controlling for an increase in quality over time, we find that the cost of the proposal is associated with a more detailed analysis.

\section{Conclusions}

We draw three conclusions from our analysis. We find that EU impact assessments have gotten more informative from 2003 to 2007, but many are still missing important information such as the monetization of benefits, calculation of net benefits, and various analytical 
assumptions. We also find that the quality of EU impact assessments that report total costs greater than $\$ 100$ million is similar to that of regulatory impact analyses in the U.S. Finally, we provide evidence that the quality of EU impact assessment increases with the expected cost of the proposal, which is consistent with the proportionality principle.

We believe that the resources expended on an analysis should be related to the likely value of that information (Raiffa, 1968). In theory, the proportionality principle allows for a sensible resource allocation among various policy proposals. In practice, however, the proportionality principle is too vague to appropriately allocate resources and is a source of confusion even to officials within the European Commission. Although our specific conclusions are consistent with the application of the proportionality principle, we cannot determine whether the principle is applied correctly for all impact assessments. The principle, as currently applied, also prevents a direct analysis of the performance of the EU impact assessment system.

We believe that the Commission should be more precise, stating expectations for analysis of different types of initiatives or levels of impacts. We recommend that the EU explicitly require that more economically significant initiatives receive higher levels of scrutiny, as is currently done in the U.S. for proposed regulations. Furthermore, the EU should identify the level of analysis that is expected for each policy proposal beforehand. This requirement would make it easier to identify analyses that fall short of expectations, thus creating a mechanism for holding the EU more accountable.

The EU should also consider releasing an annual report on the benefits and costs of its major initiatives, similar to an annual report issued by the U.S. government. This report would allow the EU to keep track of the economic impact of its initiatives over time and get a better sense of the overall economic impacts of its policies.

U.S. decision makers may also have something to learn from EU requirements for analysis. The range of initiatives that are scrutinized in Europe is much broader. Perhaps it is time that the U.S. expanded the reach of economic analysis to include laws, policies, and smaller regulations. At the same time, it should consider adopting a more refined version of the proportionality principle that takes into account the likely value of doing additional policy analysis.

If the U.S. decides to expand its analytical capability, it may also want to give more thought to how to produce studies that are less likely to be biased. It is frequently the case that agencies charged with implementing a policy also play a key role in the economic analysis of that policy. This creates an inherent conflict that could reduce the real (or perceived) quality of analysis. To address this issue, the U.S. government, and perhaps the EU, might consider creating an independent agency along the lines of the Federal Reserve, to actually do cost-benefit analysis for important public policy issues (Hahn and Tetlock, 2007).

The U.S. could also learn from the EU's decision to commission an external evaluation of its system. This evaluation included, among other things, a scorecard of different measures of quality for all IAs completed from 2003 to 2006 (The Evaluation Partnership, 2007). One key summary measure that both governments may want to consider including is the fraction of policies that are likely to pass a benefit-cost test.

In general, we believe there are substantial opportunities for agencies in different countries to borrow policy innovations from each other. While political constraints and policy objectives are likely to differ across countries, our analysis suggests there is great potential for learning from the successes and failures of the many ongoing attempts to improve the evaluation of policies and laws. 


\section{References}

Breyer, Stephen. 2006. Breaking the Vicious Circle: Toward Effective Risk Regulation. Cambridge: Harvard University Press.

Clinton, William J. 1993. "Regulatory Planning and Review." Executive Order 12,866. Washington, DC: General Printing Office (September).

$<$ http://www.archives.gov/federal-register/executive-orders/pdf/12866.pdf $>$.

Danish Environmental Assessment Institute (IMV). 2006. "Getting Proportions Right: How far should EU impact assessments go?” Denmark: Environmental Assessment Institute.

Environmental Protection Agency. 1983. "Guidelines for Performing Regulatory Impact Analysis.” Washington, DC. (Reprinted, 1991).

European Commission. 2002. "Communication from the Commission on Impact Assessment." $\operatorname{COM}(2002) 276$.

. 2004. "Impact Assessment: Next Steps: In support of competitiveness and sustainable development.” SEC(2004)1377.

. 2005. “Impact Assessment Guidelines.” SEC(2005) 791, updated in March 2006.

Farrow, Scott. 2000. "Improving Regulatory Performance: Does Executive Office Oversight Matter?” Related Publication 00. Washington, DC: AEI-Brookings Joint Center for Regulatory Studies.

Government Accountability Office. 2005. "Economic Performance: Highlights of a Workshop on Economic Performance Measures." GAO 05-796-SP, available at www.gao.gov/cgibin/getrpt?GAO-05-796SP.

Hahn, Robert W. 1996. "Regulatory Reform: Assessing the Government's Numbers," in Risks, Costs, and Lives Saved. Robert W. Hahn ed. New York: Oxford University Press.

Hahn, Robert W., Jason Burnett, Yee-Ho I. Chan, Elizabeth Mader, and Petrea Moyle. 2000. "Assessing Regulatory Impact Analyses: The Failure of Agencies to Comply With Executive Order 12,866.” Harvard Journal of Law and Public Policy. 23, pp. 859-871.

Hahn, Robert W. and Patrick Dudley. 2007. "How Well Does the Government Do Cost-Benefit Analysis?” The Review of Environmental Economics and Policy. 1(2), pp. 192-211.

Hahn, Robert W. and Paul C. Tetlock. 2007. "Has Economic Analysis Improved Regulatory Decisions?” Forthcoming in the Journal of Economic Perspectives. 
Harrington, Winston, Richard Morgenstern, and Peter Nelson. 2000. "On the Accuracy of Regulatory Cost Estimates.” Journal of Policy Analysis and Management. 19:2, pp. 297332.

Impact Assessment Board. < $\underline{\text { http://ec.europa.eu/governance/impact/iab_en.htm>. }}$.

Jacobs, Scott. 2006. "Current Trends in Regulatory Impact Analysis: The Challenges of Mainstreaming RIA into Policy-making.” Working Paper: Jacobs and Associates Inc.

Lee, Norman and Colin Kirkpatrick. 2004. "A Pilot Study of the Quality of European Commission Extended Impact Assessments.” Working Paper No. 8: Impact Assessment Research Centre.

Lussis, Benoit. 2004. EU Extended Impact Assessment Review. Working Paper: Institut pour un Développement Durable.

Morrall, John F. 1986. “A Review of the Record.” Regulation. 10:2, pp. 30-34.

Office of Management and Budget. 1992. "Circular A-94: Guidelines and Discount Rates for Benefit-Cost Analysis of Federal Programs.”

. 1996. "Economic Analysis of Federal Regulations under Executive Order 12,866." Washington, DC: U.S. Government Printing Office.

. 2005. "Validating Regulatory Analysis: Report to Congress on the Costs and Benefits of Federal Regulations and Unfunded Mandates on State, Local, and Tribal Entities." Washington, DC: Office of Information and Regulatory Affairs.

. 2006. "Report to Congress on the Costs and Benefits of Federal Regulations and Unfunded Mandates on State, Local, and Tribal Entities.” Washington, DC: Office of Information and Regulatory Affairs. Washington, DC: Office of Information and Regulatory Affairs.

Opoku, Camilla and Andrew Jordan. 2004. "Impact Assessment in the EU: A Global Sustainable Development Perspective.” Berlin Conference on the Human Dimension of Global Environmental Change.

Raiffa, Howard. 1968. Decision Analysis: Introductory Lectures on Choices Under Uncertainty. Reading, MA: Addison-Wesley Publishing Company, Inc.

Reagan, Ronald. 1981. "Executive Order 12,291: Federal Regulation.” Public Papers of the Presidents. Washington, DC: General Printing Office (February). $<$ http://www.archives.gov/federal-register/codification/executive-order/12291.html $>$.

Renda, Andrea. 2006. "Impact Assessment in the EU: The State of the Art and the Art of the State.” Brussels: Center for European Policy Studies. 
Snyder, Brett. 1996. “EPA Guidelines for Regulatory Impact Analysis.” Washington, DC: U.S. Environmental Protection Agency.

Sunstein, Cass R. 2002. The Cost-Benefit State: The Future of Regulatory Protection. Chicago: American Bar Association.

Tengs, Tammy O., Miriam E. Adams, Joseph S. Pliskin, Dana Gelb-Safran, Joanna E. Siegel, Michael C. Weinstein, and John D. Graham. 1995. "Five-Hundred Life-Saving Interventions and Their Cost-Effectiveness.” Risk Analysis. 15:3, pp. 369-390.

Tengs, Tammy O. and John D. Graham. 1996. "The Opportunity Costs of Haphazard Social Investments in Life-Saving,” in Risks, Costs, and Lives Saved. Robert W. Hahn ed. New York: Oxford University Press.

Vibert, Frank. 2004. “The EU’s New System of Regulatory Impact Assessment - A Scorecard.” European Policy Forum.

Weidenbaum, Murray. 1997. Regulatory Process Reform: From Ford to Clinton. Regulation: The Cato Review of Business and Government. 20:1, pp. 20-26. 
Figures and Tables

(in order that they appear in the text)

Table 1: Scorecard Items and Binding EU Impact Assessment Summary Statistics, 2003-2007

\begin{tabular}{|c|c|c|c|c|}
\hline Item & Category and Item Description & $\begin{array}{l}\text { Percent of IAs } \\
\text { that Include } \\
\text { Scorecard Item } \\
(\mathbf{n}=111) \\
\end{array}$ & $\begin{array}{c}\text { Percent in } \\
2003(n=15)\end{array}$ & $\begin{array}{l}\text { Percent in } \\
2007 \\
(\mathbf{n}=25)\end{array}$ \\
\hline & Index (mean) & 0.45 & 0.40 & 0.55 \\
\hline & Estimation of Costs & & & \\
\hline 1 & Stated costs exist & $85 \%$ & $60 \%$ & $96 \%$ \\
\hline 2 & Quantified at least some costs & $56 \%$ & $40 \%$ & $84 \%$ \\
\hline 3 & Monetized at least some costs & $55 \%$ & $40 \%$ & $76 \%$ \\
\hline \multirow[t]{2}{*}{4} & $\begin{array}{l}\text { Provided point estimate or range } \\
\text { of total costs }\end{array}$ & $43 \%$ & $29 \%$ & $52 \%$ \\
\hline & Estimation of Benefits & & & \\
\hline 5 & Stated benefits exists & $95 \%$ & $93 \%$ & $100 \%$ \\
\hline 6 & Quantified at least some benefits & $41 \%$ & $67 \%$ & $40 \%$ \\
\hline 7 & Monetized at least some benefits & $34 \%$ & $53 \%$ & $40 \%$ \\
\hline 8 & $\begin{array}{l}\text { Provided point estimate or range } \\
\text { of total benefits }\end{array}$ & $17 \%$ & $20 \%$ & $20 \%$ \\
\hline 9 & $\begin{array}{l}\text { Comparison of Costs and Benefits } \\
\text { Calculated net benefits or cost } \\
\text { effectiveness }\end{array}$ & $26 \%$ & $27 \%$ & $24 \%$ \\
\hline & Evaluation of Alternatives & & & \\
\hline 10 & $\begin{array}{l}\text { Considered at least one } \\
\text { alternative }\end{array}$ & $96 \%$ & $87 \%$ & $100 \%$ \\
\hline 11 & Quantified alternatives (costs) & $37 \%$ & $13 \%$ & $64 \%$ \\
\hline 12 & Monetized alternatives (costs) & $33 \%$ & $7 \%$ & $60 \%$ \\
\hline 13 & Quantified alternatives (benefits) & $20 \%$ & $33 \%$ & $28 \%$ \\
\hline 14 & Monetized alternative (benefits) & $14 \%$ & $13 \%$ & $24 \%$ \\
\hline 15 & $\begin{array}{l}\text { Net benefits or cost } \\
\text { effectiveness of alternatives }\end{array}$ & $20 \%$ & $27 \%$ & $12 \%$ \\
\hline
\end{tabular}

Source: Authors' calculations and Hahn and Dudley (2007).

Note: The U.S. RIAs range from 1982-1999. 
Figure 1: Mean Scores on Index by Year

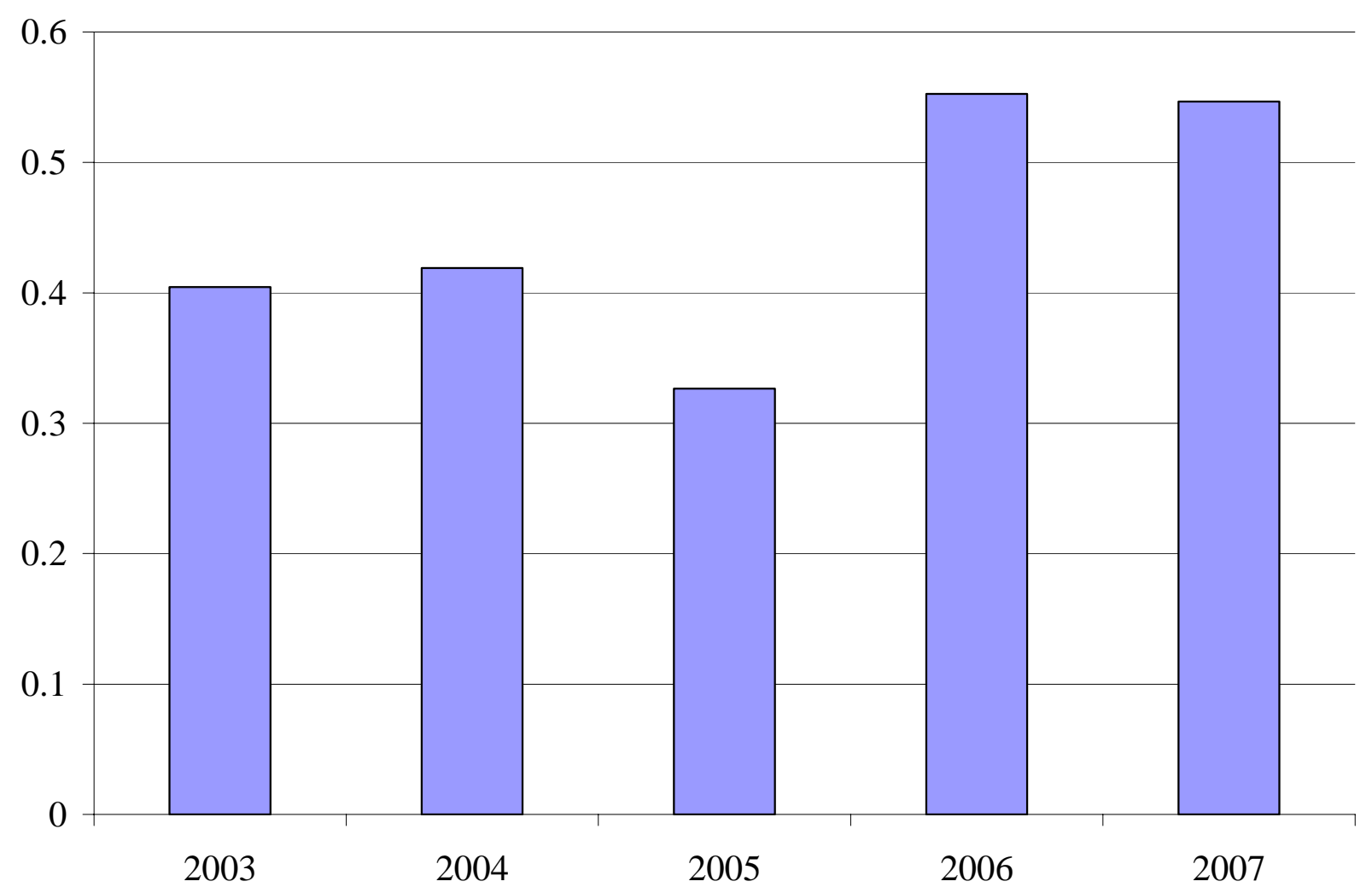

Notes: For 2003-2007, the number of observations summarized is 15, 21, 29, 21, and 25, respectively. 
Figure 2: Percentage of Impact Assessments that Report Cost Information



Notes: For 2003-2007, the number of observations summarized is 15, 21, 29, 21, and 25, respectively. 
Figure 3: Percentage of Impact Assessments that Report Benefit Information

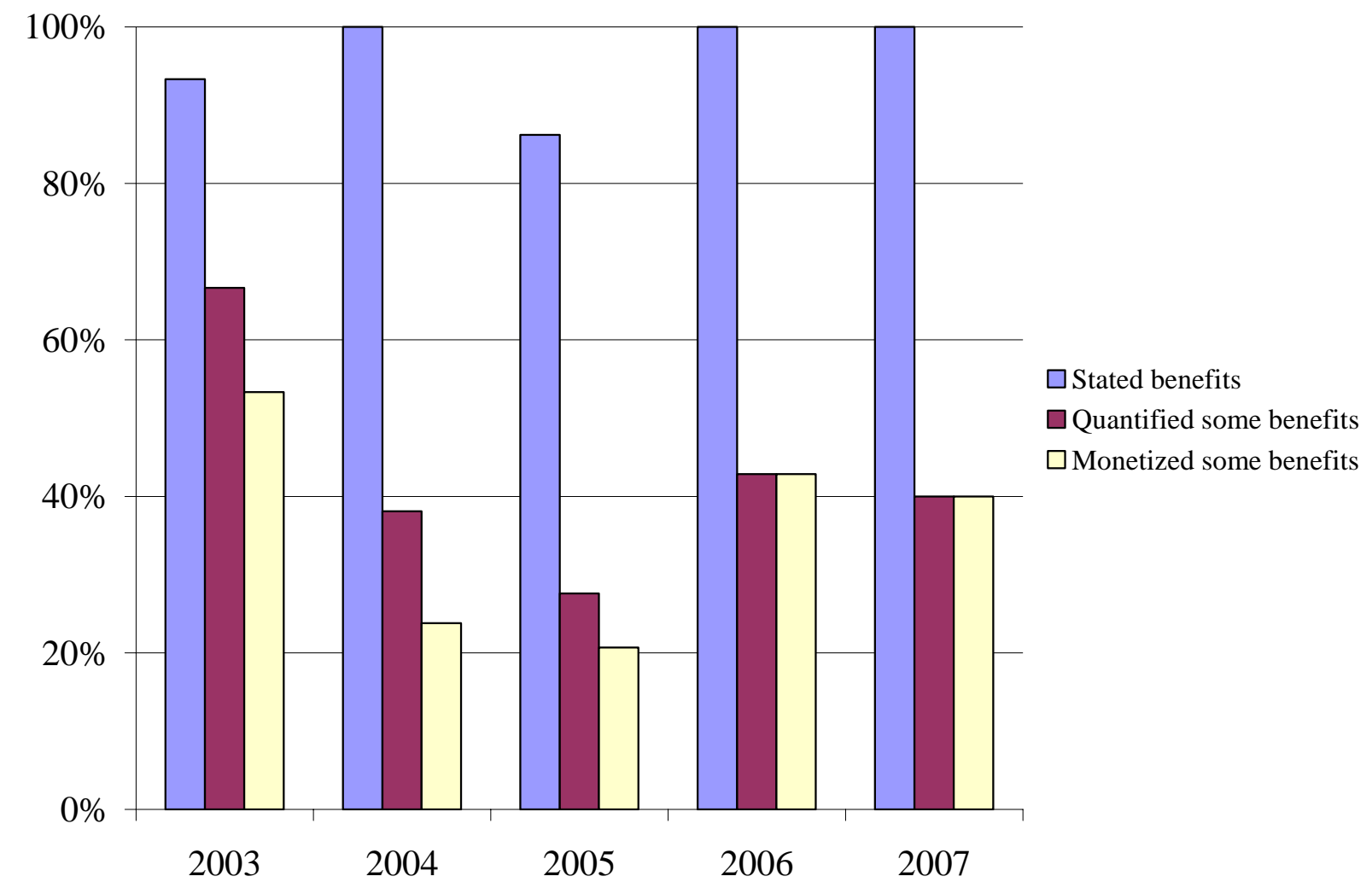

Notes: For 2003-2007, the number of observations summarized is 15, 21, 29, 21, and 25, respectively. 
Figure 4: Percentage of Impact Assessments that Report Information on Alternatives

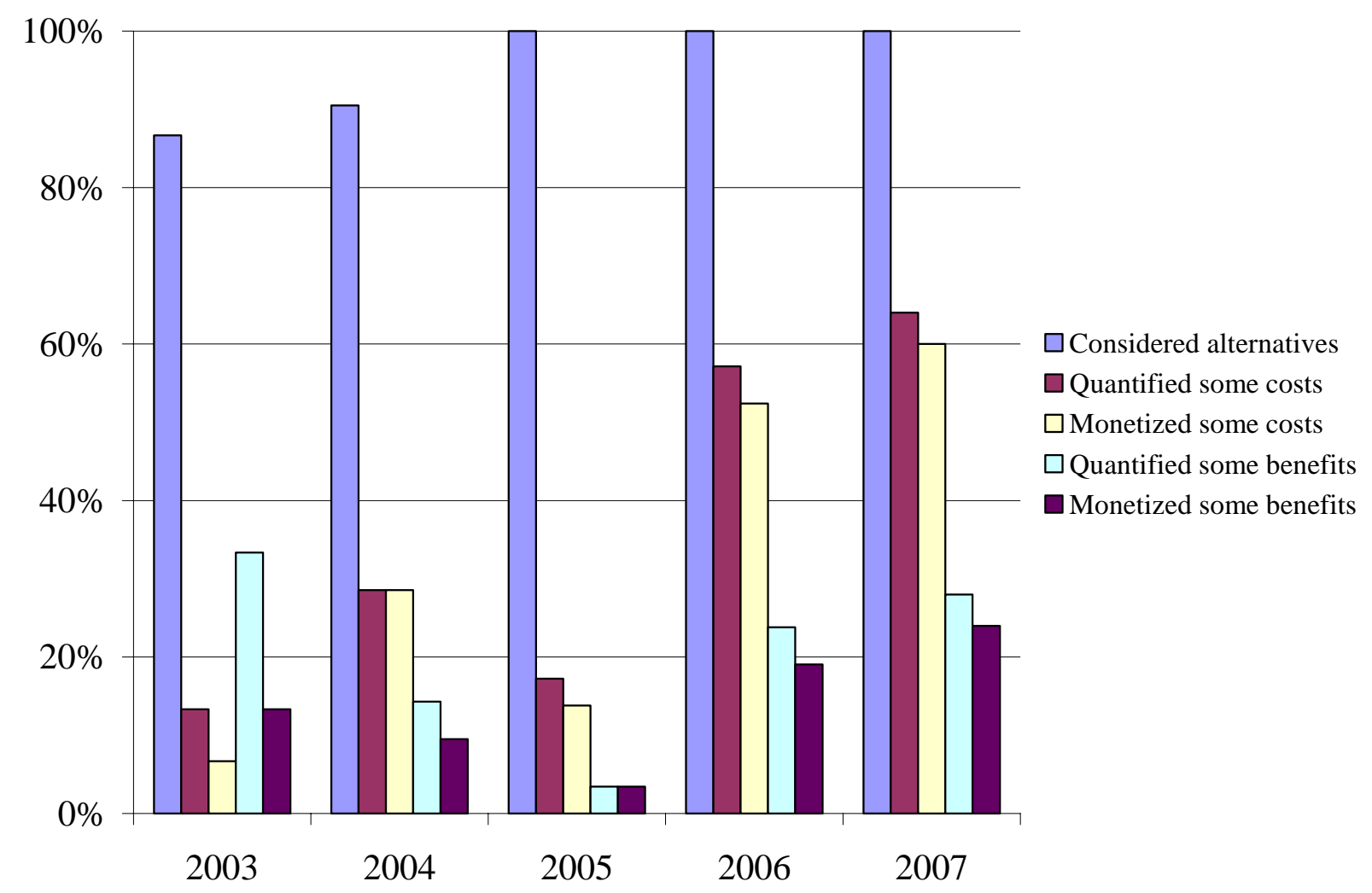

Notes: For 2003-2007, the number of observations summarized is 15, 21, 29, 21, and 25, respectively. 
Figure 5: Percentage of Impact Assessments that Report

Net Benefits or Cost Effectiveness

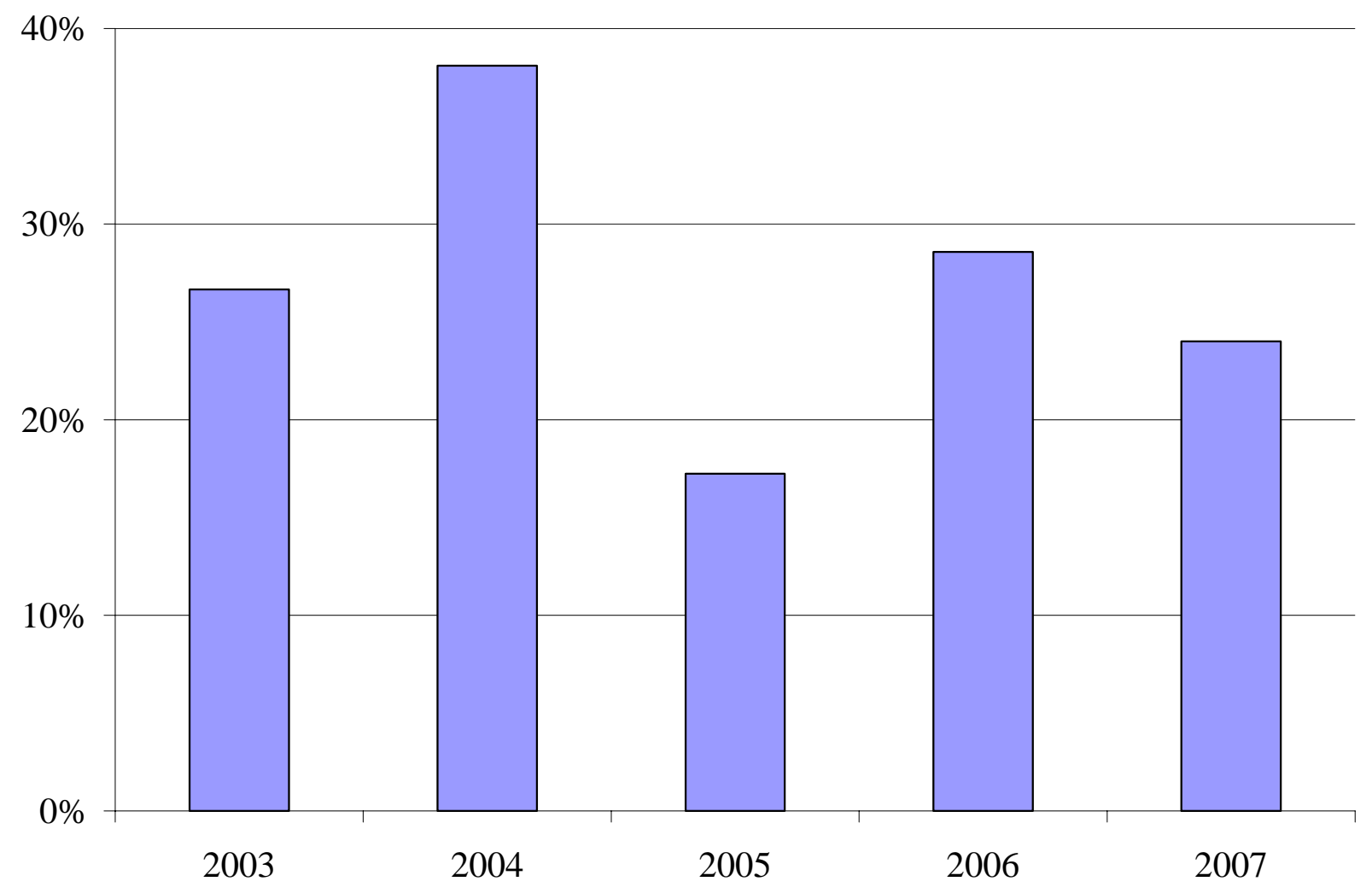

Notes: For 2003-2007, the number of observations summarized is 15, 21, 29, 21, and 25, respectively. 
Figure 6: Percentage of Impact Assessments that Report

Information in the Executive Summary

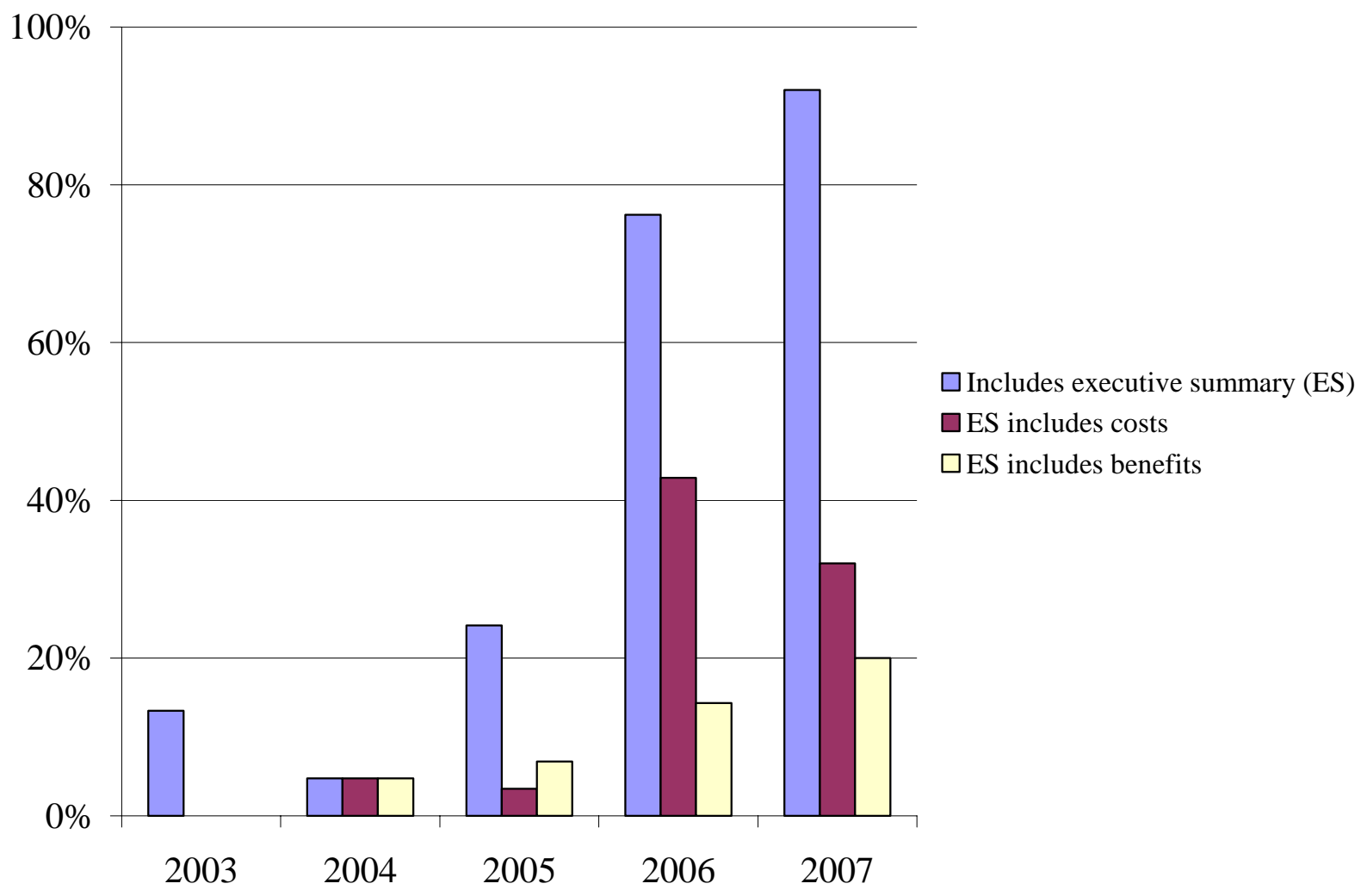

Notes: For 2003-2007, the number of observations summarized is 15, 21, 29, 21, and 25, respectively. 
Figure 7: Percentage of Impact Assessments that Report the Euro Year

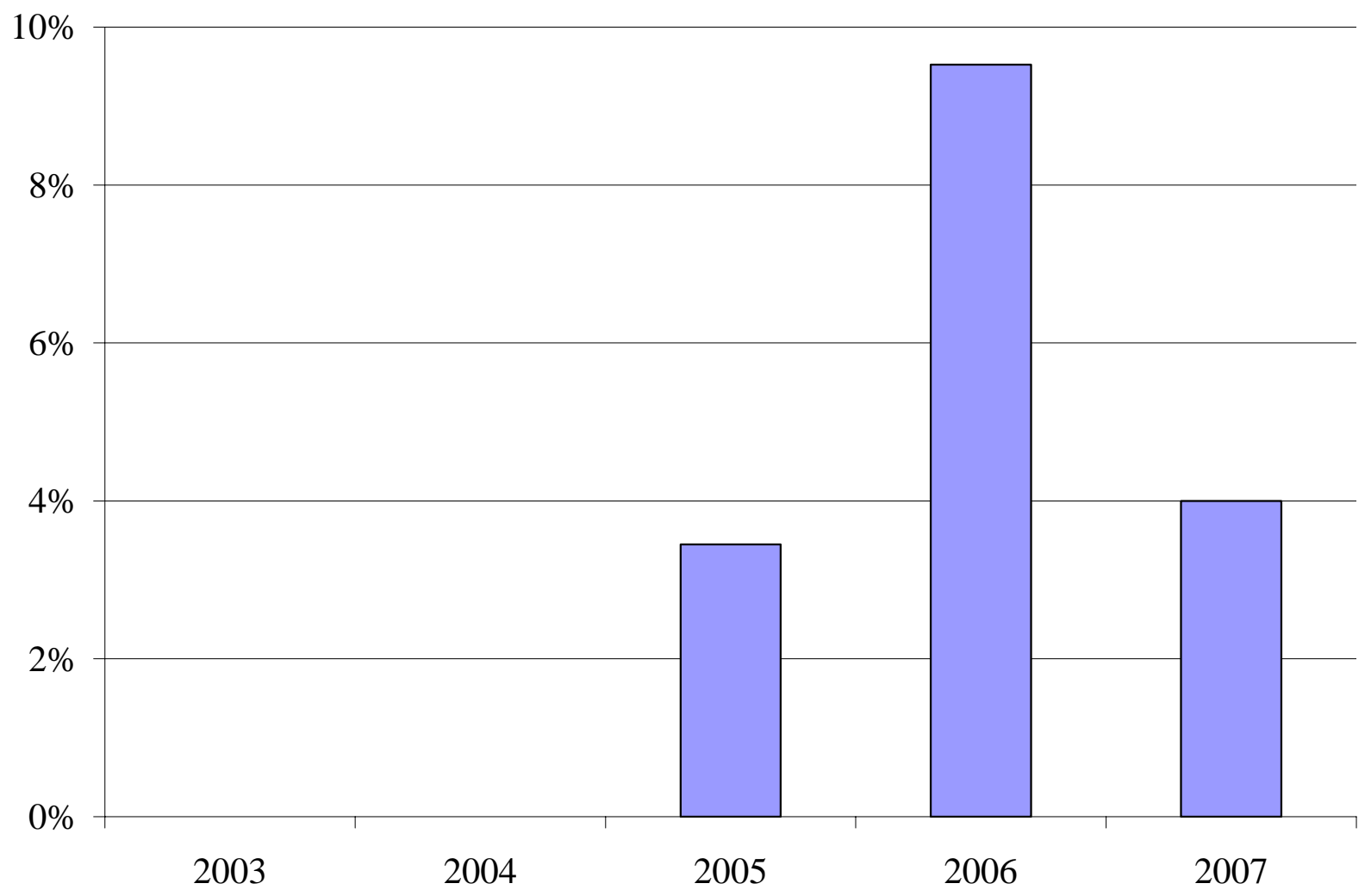

Notes: For 2003-2007, the number of observations summarized is $15,21,29,21$, and 25 , respectively. 
Table 2: A Comparison of “Significant” RIAs and IAs, 1982-1999 and 2003-2007

\begin{tabular}{|c|c|c|c|c|}
\hline Item & Category and Item Description & $\begin{array}{l}\text { Percent of EU } \\
\text { IAs Reporting } \\
\text { Scorecard } \\
\text { Item }(\mathbf{n}=\mathbf{1 1 1})\end{array}$ & $\begin{array}{c}\text { Percent of } \\
\text { “Significant" } \\
\text { IAs Reporting } \\
\text { Scorecard } \\
\text { Item }(n=22)\end{array}$ & $\begin{array}{c}\text { Percent of } \\
\text { U.S. RIAs } \\
\text { Reporting } \\
\text { Scorecard } \\
\text { Item }(n=74)\end{array}$ \\
\hline & Index (mean) & 0.45 & 0.71 & 0.71 \\
\hline & Estimation of Costs & & & \\
\hline 1 & Stated costs exist & $85 \%$ & $100 \%$ & $100 \%$ \\
\hline 2 & Quantified at least some costs & $56 \%$ & $100 \%$ & $100 \%$ \\
\hline 3 & Monetized at least some costs & $55 \%$ & $100 \%$ & $100 \%$ \\
\hline \multirow[t]{2}{*}{4} & $\begin{array}{l}\text { Provided point estimate or range } \\
\text { of total costs }\end{array}$ & $43 \%$ & $100 \%$ & $88 \%$ \\
\hline & Estimation of Benefits & & & \\
\hline 5 & Stated benefits exists & $95 \%$ & $100 \%$ & $95 \%$ \\
\hline 6 & Quantified at least some benefits & $41 \%$ & $59 \%$ & $88 \%$ \\
\hline 7 & Monetized at least some benefits & $34 \%$ & $59 \%$ & $51 \%$ \\
\hline 8 & $\begin{array}{l}\text { Provided point estimate or range } \\
\text { of total benefits }\end{array}$ & $17 \%$ & $41 \%$ & $38 \%$ \\
\hline \multirow[t]{2}{*}{9} & $\begin{array}{l}\text { Comparison of Costs and Benefits } \\
\text { Calculated net benefits or cost } \\
\text { effectiveness }\end{array}$ & $26 \%$ & $64 \%$ & $68 \%$ \\
\hline & Evaluation of Alternatives & & & \\
\hline 10 & $\begin{array}{l}\text { Considered at least one } \\
\text { alternative }\end{array}$ & $96 \%$ & $95 \%$ & $80 \%$ \\
\hline 11 & Quantified alternatives (costs) & $37 \%$ & $64 \%$ & $66 \%$ \\
\hline 12 & Monetized alternatives (costs) & $33 \%$ & $59 \%$ & $66 \%$ \\
\hline 13 & Quantified alternatives (benefits) & $20 \%$ & $36 \%$ & $51 \%$ \\
\hline 14 & Monetized alternative (benefits) & $14 \%$ & $32 \%$ & $32 \%$ \\
\hline 15 & $\begin{array}{l}\text { Net benefits or cost effectiveness } \\
\text { of alternatives }\end{array}$ & $20 \%$ & $50 \%$ & $46 \%$ \\
\hline
\end{tabular}

Source: Authors' calculations and Hahn and Dudley (2007).

Note: The U.S. RIAs range from 1982-1999. 
Figure 8: Scores on Index by the Logarithm of Cost

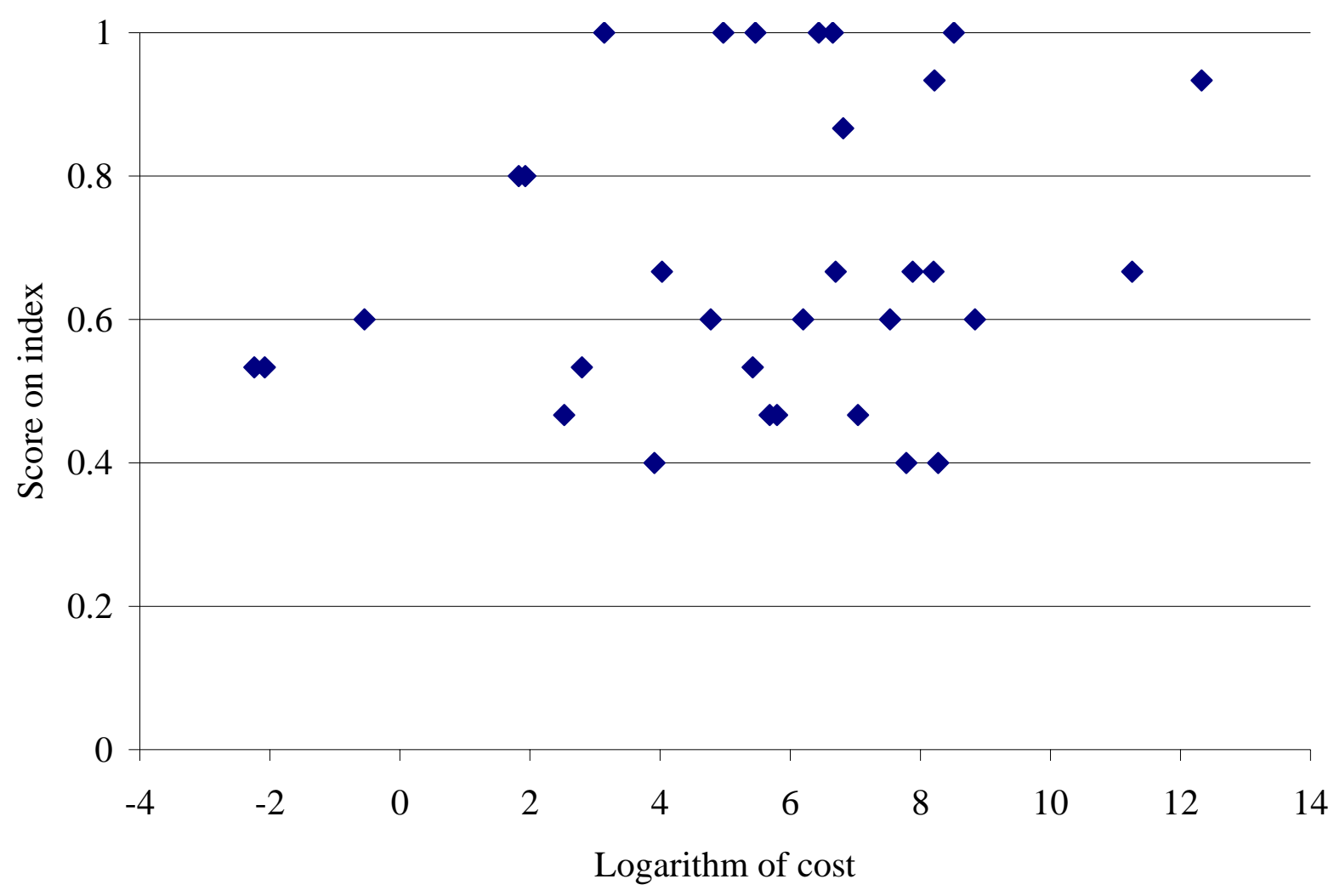

